16.8\%). $91.2 \%(4048 / 4437)$ of participants consented to data linkage; of these $83.7 \%$ (3391) could be linked to GUMCADv2. Consent did not differ by age or gender, but washigher among men who have sex with men than heterosexual men $(95.5 \%$ vs. $88.4 \%$; p < 0.01$)$, and lower among Black Caribbean than white participants $(87.1 \%$ vs $93.8 \%, \mathrm{p}<0.01)$. Compared to all clinic attendees at study sites in the study period, a higher proportion of participants were $<25$ years $(30.8 \%$ vs $37.1 \%, \mathrm{p}<0.001)$, were black Caribbean $(8.1 \%$ vs $14.5 \%, \mathrm{p}<0.001)$, and had a same-day sexual health screen $(70.2 \%$ vs $77.4 \%, \mathrm{p}<0.001)$ or a chlamydia/gonorrhoea diagnosis $(6.4 \%$ vs $7.7 \%$ p $<0.01)$ recorded on GUMCADv2.

Conclusion Online behavioural surveys with data linkageto EPRsare highly acceptable to sexual health clinic attendees and technically feasible, and could improve the knowledgebase needed to tailor STI risk reduction efforts. However participants with higher risk profiles may be oversampled. Poor recruitment in some clinics was likely due to limited availability of clinic staff to facilitate and encourage use ofclinic tablets

\section{P3.29 PREVALENCE OF HIV, SIFILIS, HEPATITIS B AND HEPATITIS C IN THE INMATES OF THE PENITENTIARY COMPLEX OF VALE DO ITAJAÍ-SC}

Bruna Ribas Ronchi, Gabriela Marçal Rios, Rosalie Kupka Knoll, Carolina Cardoso. UNIVALI, Itajaí-SC, Brazil

\subsection{6/sextrans-2017-053264.266}

Introduction To establish prevalence and identify risk factors for HIV, Syphilis, Hepatitis B and Hepatitis C infections in the Private Population of Freedom (PPF) in the ComplexoPenitenciário do Vale do Itajaí-Canhanduba, Itajaí, Santa catarina, Brazil.

Methods In the period between December of the year 2015 and August of the year 2016 a research was carried out at the Canhanduba penitentiary, Itajaí-SC, with quantitative and prospective character. The data collection was performed through a review of 921 medical records and rapid tests provided by the Ministry of Health - Brazil and the State Department of Health - SC. There were 655 interns participating initially, of these 170 did not want to be part of the research and 470 accepted to perform the tests.

Results The prevalence of infections in this population was 2.9\% for HIV, 5.9\% for Syphilis, 1.0 for HBV and 2.5\% for HCV. This population were consisted of men, mostly in the age group between 20 and 40 years. It was possible to identify a high consumption of all kind of drugs in this population, being alcohol, marijuana and cocaine the most reported. Conclusion In view of the observed aspects, it was possible to conclude that PPLF has a higher prevalence for infectious diseases when compared to the free population, since most of them present with a few years of studies, in use of illicit drugs and in activity unprotected sex. In addition to being exposed to a crowded environment, precarious and with a high turnover of people. The statistical data on this subject in Brazil are rare and out of date, thus not demonstrating the real epidemiological and serological situation of this population as a whole, so studies in several areas must be carried out in order to formulate new strategies of action.

\section{P3.30 PREVALENCE AND RISK BEHAVIOURS FOR SYMPTOMATIC SEXUALLY TRANSMITTED INFECTION AMONG THE RURAL POPULATION IN CENTRAL BRAZIL}

${ }^{1}$ KAA Caetano, SA Teles, MA Matos, ${ }^{2}$ MAS Carneiro, RS Pinheiro, ${ }^{3}$ LC Moraes, 'LRC Rosa, ${ }^{1}$ TF Amorim, ${ }^{1}$ TLS Martins, ${ }^{1}$ BCS Alves, ${ }^{1}$ GRC Silva. ${ }^{1}$ Faculty of Nursing, Federal University of Goias, Goiania, Brazil; ' Institute of Tropical Pathology and Public Health, Federal University of Goias, Goiania, Brazil; ${ }^{3}$ Municipal Health Secretariat of Jatai, Brazil

\subsection{6/sextrans-2017-053264.267}

Introduction A million people every day worldwide contract a Sexually Transmitted Infection (STI). In Brazil, studies show that rural living presents adverse conditions and promotes life behaviours that favour the acquisition of such diseases. The objective of this investigation was to estimate the prevalence of symptomatic STIs and to analyse the risk behaviours for these infections among rural settlers from the southwest of Goiás, Central Brazil.

Methods This is an observational, analytical and cross-sectional study. From May to June 2011, 395 individuals aged 12 years or older living in settlements in southwestern Goiás, Central Brazil, were recruited. All participants were interviewed by means of a structured questionnaire, containing questions about sociodemographic data and risk behaviours for STIs. The outcome variable was the clinical presentation of one of the following STI symptoms over the previous 12 months: vaginal discharge, urethral discharge, genital ulcers, pelvic inflammatory disease, and anogenital warts. The study was approved by the Research Ethics Committee of the Federal University of Goiás.

Results Of the total, $51.6 \%$ were male, $39.5 \%$ were aged between 12 and 40 years, and $42.5 \%$ had 4 or fewer years of study. The majority were married (68.4\%), from Goiás (79\%), and were Catholic (51.9\%). The prevalence for symptomatic STIs among the settlers was $20.5 \%$. It was observed that being male (adjusted OR: 0.17, $\mathrm{p}=0.00$ ), drinking alcohol (adjusted OR: 1.75, p=0.05), and life history in rural encampment. (adjusted OR: 2.78, p=0.00) were variables associated with STIs.

Conclusion The results support the need for effective strategies for prevention and control of STIs among the rural population, especially settlers, a population with significant potential in the chain of transmission of sexual infections. Health education and rapid testing for STIs should be implemented for individuals of rural encampment in Brazil.

\section{P3.31 HIGH RISK BEHAVIOURS AND SYPHILIS/HIV INFECTION AMONG MEN WHO HAVE SEX WITH MEN AGED 50 YEARS AND OLDER IN SHENZHEN, CHINA}

${ }^{1}$ Cai Yumao, ${ }^{1}$ Hong Fuchang, 'Wen Lizhang, 'Lai Yonghui, ${ }^{1} Y u$ Weiye, ${ }^{2}$ Liu Hui. ${ }^{1}$ Shenzhen Centre for Chronic Disease Control and Prevention, Shenzhen, Guangdong Province, China; ${ }^{2}$ National Centre for AIDS/STD Control and Prevention, China CDC

\subsection{6/sextrans-2017-053264.268}

Introduction The national average HIV prevalence among men who have sex with men in China increased from $1.4 \%$ in 2005 to $8.0 \%$ in 2015 . There is a significant increase in the number of HIV new infections in individuals over 50 years of age in China and other countries. In China the prevalence of syphilis/HIV infection among MSM over 50 years is increasingly high but few reports pay attention to it. Our study was to investigate the high risk behaviours and syphilis/HIV 